\title{
Non-radiative wireless energy transfer with single layer dual-band printed spiral resonator
}

\author{
Lai Ly Pon, Sharul Kamal Abdul Rahim, Chee Yen Leow, Tien Han Chua \\ Wireless Communication Centre (WCC), School of Electrical Engineering, Universiti Teknologi Malaysia, Malaysia
}

\begin{tabular}{l}
\hline Article Info \\
\hline Article history: \\
Received Jan 2, 2019 \\
Revised Mar 8, 2019 \\
Accepted Mar 29, 2019 \\
\hline Keywords: \\
Dual-band \\
Non-radiative \\
Power transfer efficiency \\
Printed spiral resonator \\
Wireless energy transfer \\
\hline
\end{tabular}

\begin{abstract}
Accomplishing equilibrium in terms of transfer efficiency for dual-band wireless energy transfer (WET) system remains as one of key concerns particularly in the implementation of a single transmitter device which supports simultaneous energy and data transfer functionality. Three stages of design method are discussed in addressing the aforementioned concern. A single layer dual-band printed spiral resonator for non-radiative wireless energy transfer operating at $6.78 \mathrm{MHz}$ and $13.56 \mathrm{MHz}$ is presented. By employing multi-coil approach, measured power transfer efficiency for a symmetrical link separated at axial distance of $30 \mathrm{~mm}$ are $72.34 \%$ and $74.02 \%$ at the respective frequency bands. When operating distance is varied between $30 \mathrm{~mm}$ to $38 \mathrm{~mm}$, consistency of simulated peak transfer efficiency above $50 \%$ is achievable.
\end{abstract}

Copyright () 2019 Institute of Advanced Engineering and Science. All rights reserved.

\section{Corresponding Author:}

Sharul Kamal Abdul Rahim,

Wireless Communication Centre (WCC),

School of Electrical Engineering, Universiti Teknologi Malaysia,

81310 UTM Skudai, Johor Bahru, Malaysia.

Email: sharulkamal@fke.utm.my

\section{INTRODUCTION}

Multifunctional loops for simultaneous power and data or simultaneous wireless charging at different standards are made possible with coils designed to support more than one frequency band. There are currently two main standards for wireless charging. Wireless Power Consortium (WPC) or better known as Qi is one of the leading standard operating in low frequency (LF) band, $110 \mathrm{kHz}$ to $205 \mathrm{kHz}$ [1]. AirFuel Alliance is the merger between Power Matters Alliance (PMA) and the Alliance for Wireless Power (A4WP, also known as Rezence). A4WP employs magnetic resonance coupling technique operating at 6.78 $\mathrm{MHz} \pm 15 \mathrm{kHz}$ [2] while both $Q i$ and PMA engage in inductive charging method. The operating frequency for PMA standard is $277 \mathrm{kHz}$ to $357 \mathrm{kHz}$ [3].

There are two foremost approaches used in the design of dual-band coils specifically multi-coil [4-9], and single-coil approach [10-15]. The latter has a slight edge with lesser cross coupling [10]. Cross coupling mitigation is proposed with a coplanar coils structure while geometrical area reduction is considered with a coaxial structure [8]. Nevertheless, in order to concurrently capitalize on efficiency at two different frequencies in a single transmitter, it is recommended to design two separate coils which facilitate independent selection of inductance and quality factor [5]. A compact two circular DGS resonator with independent coupling is proposed in [16]. Concurrent high-power transfer is reported for both frequency bands investigated. Similar findings are reported in [17] using a single compensation network for dual mode inductor designed.

The challenge to achieve simultaneous high power transfer for dual-band frequency in single-coil approach is still achievable as demonstrated in [18-19] with the introduction of dual-band repeater or also known as intermediate coils. However, additional repeater means more space allocation is required beside frequency splitting occurrence for one of the frequency bands due to strong coupling. Furthermore, one needs 
to exercise caution in designing repeater as transfer efficiency is greatly affected by parasitic resistance originating from repeater. As such, a dual-band printed spiral resonator sharing a single substrate is proposed in this paper. With a space-conscious design, the proposed design aims to achieve a transfer efficiency balance between the designated frequencies bands.

\section{RESEARCH METHOD}

There are three design stages involved as illustrated in Figure 1. Full wave electromagnetic simulator tool, CST Microwave Studio is employed for modelling and optimization. The foundation of first loop resonator design is bounded by the restricted and preliminary geometrical values namely number of turns, $n_{f l}$, width and spacing of conductive trace, $w_{f l}, s_{f l}$. Initial stage encompasses design and optimization workflow of loop resonator to be functioning at the first resonance frequency. Innermost length of first loop resonator designed will then be acknowledged as another constraint parameter in designing second loop resonator in Stage B. If Stage B and Stage A are reversed, then the outermost length of second loop resonator designed will consequently be recognized as a constraint parameter in designing first loop resonator. The final stage involves impedance matching where separate optimization processes are deem necessary in order to acquire concurrent maximum transfer efficiency for both frequency bands under investigation. The correlation between optimal transfer distance and outermost side length of loop at maximum excited magnetic field derived in [20] yields.

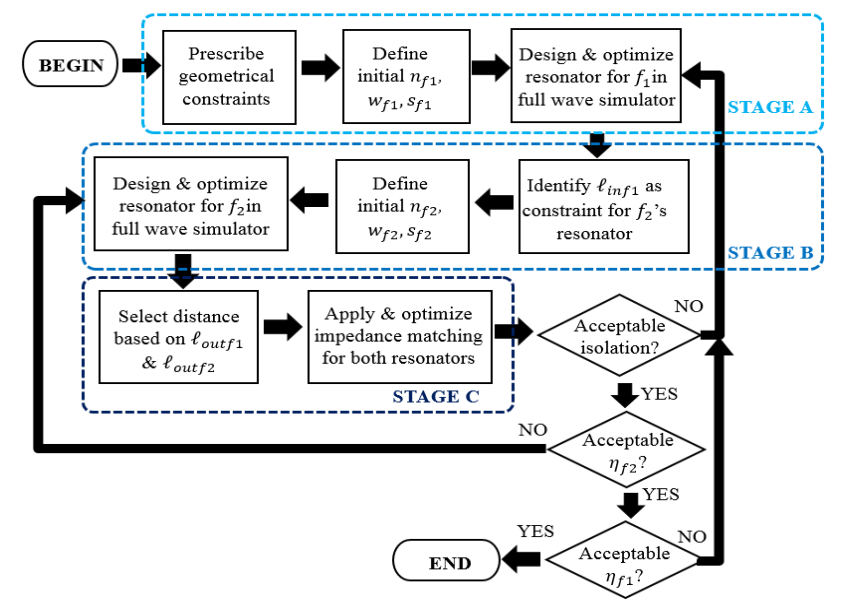

Figure 1. Three stages of simulation plan for dual-band printed spiral resonator

$$
z_{\text {op }}=\ell_{\text {out }}(2.544)^{-1}
$$

As such, a compromise will be performed in the selection of axial distance before initiating any impedance matching work particularly when there is significant variance between outermost length of the first and second loop resonator. An existing macro for matching circuits in CST Microwave Studio, Mini Match is employed to achieve simultaneous conjugate matching at 50-ohm port terminations and convergence at resonance frequencies. Comprises of a series and a shunt capacitor, $L$-match network is connected for both resonators which shares a single substrate. For a dual-band printed spiral resonator with transmitting terminals at port 1 and port 3, transfer efficiency can be extracted from transmission coefficients, $S_{21}$ for first frequency band while $S_{43}$ for the second frequency band.

Multi-coil approach is opted in designing inductive loops operating in more than one resonance frequency in order to achieve equilibrium in terms of transfer efficiency for all frequency bands under investigation. The resonance band concerned here is $B 1$ at $6.78 \mathrm{MHz}$ and $B 2$ at $13.56 \mathrm{MHz}$. The total proposed dimension is $80 \mathrm{~mm}$ by $90 \mathrm{~mm}$ with a FR-4 thickness of $1.6 \mathrm{~mm}$. As shown in Figure 2, outermost lengths of top layer, $d t_{o}$ and bottom layer, $d b_{o}$ are $70 \mathrm{~mm}$ and $44.2 \mathrm{~mm}$ whereas the inner length of top layer, $d t_{i}$ and bottom layer, $d b_{i}$ are $55.6 \mathrm{~mm}$ and $18.6 \mathrm{~mm}$ respectively. Square spiral resonator with copper thickness of $70 \mu \mathrm{m}$ is designed on top layer which consists of three turns, $n$ with varying widths and spacing denoted by $w t_{n}$ and $s t_{n}$. Similarly, bottom layer is designed with a diverse widths, $w b_{n}$ and spacing, $s b_{n}$ and additional turns to increase coil inductance. Fabricated dual-band design is depicted in Figure 3.

Non-radiative wireless energy transfer with single layer dual-band printed spiral resonator (Lai Ly Pon) 


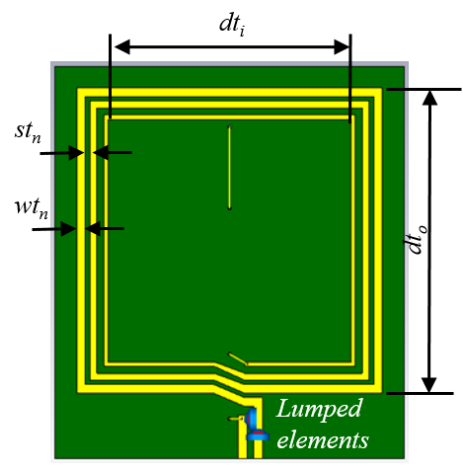

(a)

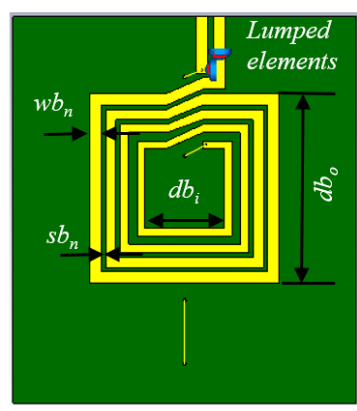

(b)

Figure 2. Proposed dual-band design, (a) Top layer, (b) Bottom layer

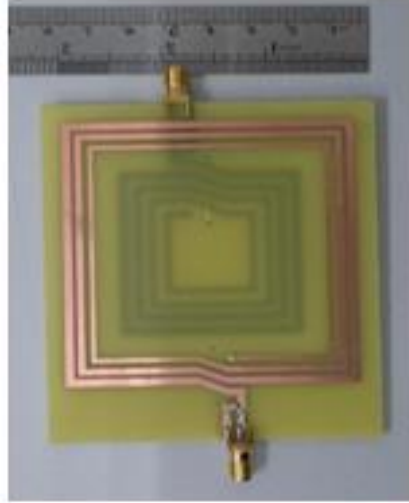

(a)

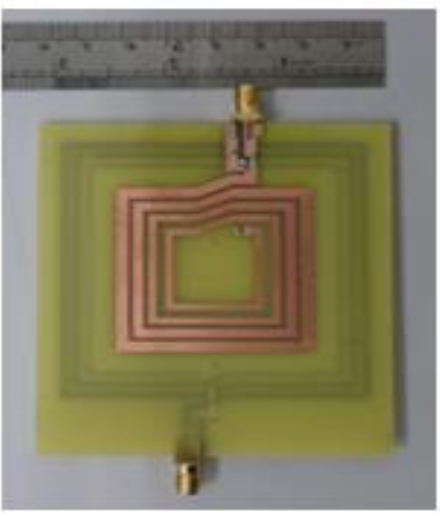

(b)

Figure 3. Fabricated dual-band design, (a) Top layer, (b) Bottom layer

In order to achieve simultaneous conjugate matching at $50 \mathrm{ohm}$ for $6.78 \mathrm{MHz}$ and $13.56 \mathrm{MHz}$ frequency bands, $L$-matching technique as proposed in [20] with a single series capacitor, $C_{s}$ and a single parallel capacitor, $C_{p}$ is utilized. Consequently, the total lumped elements employed on a transmitter is four capacitors for dual-band design. With inbuilt search algorithm in full wave finite element simulator, matching capacitors are determined to achieve resonance at B1 and B2. Simulations are then repeated based on the closest available off-the-shelves surface mount device (SMD) capacitor values. Table 1 shows the list of initial, simulated and employed matching capacitor values. Port 1 and 3 represent source loops at $13.56 \mathrm{MHz}$ and 6.78 $\mathrm{MHz}$ correspondingly.

Table 1. Selected capacitor values for impedance matching

\begin{tabular}{ccccc}
\hline Port & 1 & 2 & 3 & 4 \\
\hline Initial Matching $C_{\mathrm{s}}(\mathrm{pF})$ & 56.64 & 57.22 & 191.29 & 191.56 \\
Initial Matching $C_{p}(\mathrm{pF})$ & 67.29 & 68.89 & 644.87 & 644.66 \\
Simulated $\mathrm{C}_{\mathrm{s}}(\mathrm{pF})$ & 56 & 56 & 200 & 200 \\
Simulated $C_{p}(\mathrm{pF})$ & 68 & 68 & 620 & 620 \\
Employed $C_{\mathrm{s}}(\mathrm{pF})$ & 56 & 56 & 200 & 200 \\
Employed $C_{p}(\mathrm{pF})$ & 68 & 68 & 150 & 150 \\
\hline
\end{tabular}




\section{RESULTS AND ANALYSIS}

\subsection{Power transfer efficiency}

Since the receiving loops are represented by port 2 and 4 , the transfer efficiency for $B 1$ and $B 2$ bands can be derived from $S$-parameters, $\left|S_{21}\right|^{2}$ and $\left|S_{43}\right|^{2}$. Simulated and measured peak transfer efficiencies, $\operatorname{SimPTE}_{p B 1}, \operatorname{SimPTE}_{p B 2}, M e a P T E_{p B 1}$ and $M e a P T E_{p B 2}$ are tabulated in Table 2. The optimal axial distance, $z$ for maximum axial magnetic field with reference to outermost side-length of loop, $d_{t o}$ and $d_{b o}$ are determined based on (1). As such, the theoretical optimum distances, $z_{B 1}$ and $z_{B 2}$ computed based on proposed design are $17.37 \mathrm{~mm}$ and $27.52 \mathrm{~mm}$. With a difference of about $10 \mathrm{~mm}$, a distance selected should be of benefit for both frequency bands since both coils are etched on the same substrate. If distance selected is less than $z_{B 2}$ with the purpose of accomplishing an ideal $P T E_{B 1}$, frequency splitting at $B 2$ will be inevitable due to over coupling when receiver coil is positioned too close with source coil. Hence, distance of $30 \mathrm{~mm}$ is opted as distance for simultaneous conjugate matching at the expense of highest possible $P T E_{B I}$. Simulations and measurements for axial distances ranging from $30 \mathrm{~mm}$ till $50 \mathrm{~mm}$ are performed with with an increment step of $2 \mathrm{~mm}$ to investigate on the possibility of sustaining efficiency as depicted in Figure 4 and Figure 5 . Measurement setups with the aid of vector network analyser (VNA) are shown in the inset of Figure 4 and Figure 5 respectively.

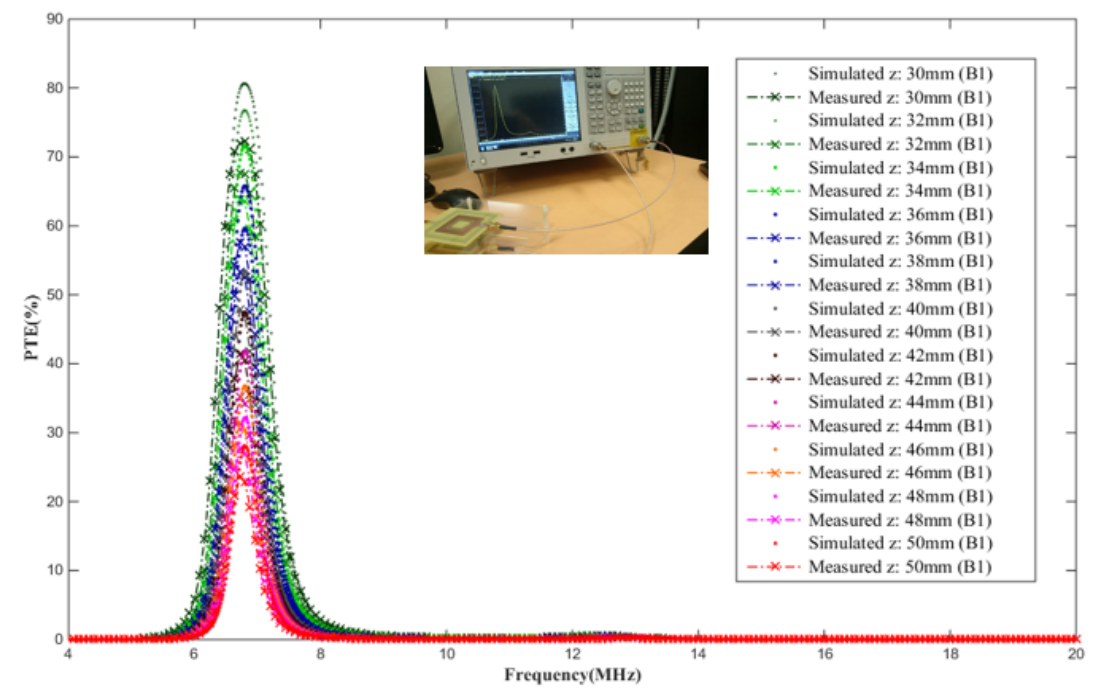

Figure 4. Simulated and measured PTE $(B 1)$ under varied operating distance

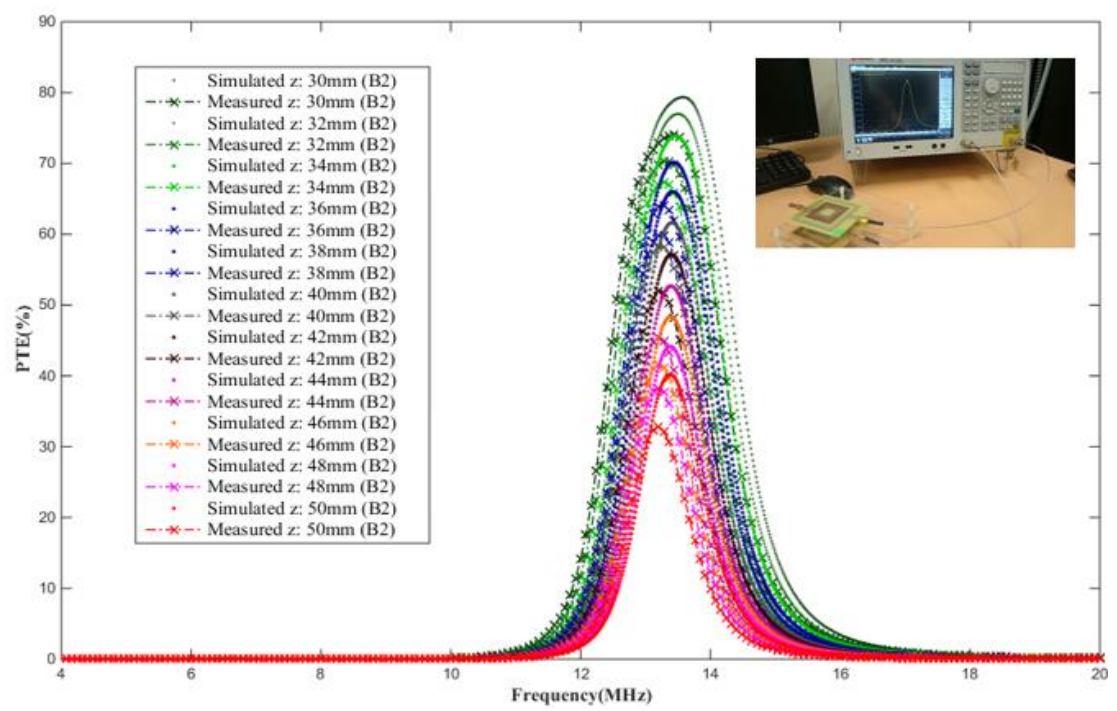

Figure 5. Simulated and measured PTE (B2) under varied operating distance 
It is observed that simulated PTE is around $80 \%$ for both frequency bands at distance of $30 \mathrm{~mm}$ when $L$-matchings are performed. Despite the fact that theoretical optimum axial distance for the lower band is ought to be lesser than $30 \mathrm{~mm}$, the presence of loops at the top layer could contribute towards the enhanced coupling in the under-coupled region which is similar with the concept of four coils in magnetic resonance coupling [21-22]. The loops for higher band etched on the top layer represent the resonator while the loops at the bottom layer are the source driving loop at $6.78 \mathrm{MHz}$. Attempt has also been made to simulate similar design on a substrate with $25 \%$ reduction of thickness. PTE for $B 1$ is found to increase by approximately $2 \%$ from $80.64 \%$ to $82.66 \%$ while PTE for $B 2$ decrease by about $0.5 \%$ from $79.35 \%$ to $78.87 \%$. Hence, the characteristic of the proposed design is not significantly affected by the thickness of substrate used. Measured peak PTE is $72.34 \%$ and $74.02 \%$ for the respective bands. Deviations between simulated and measured results could be due to deficiencies in fabrication process. Comparison with other works is summarized in Table 3. Proposed simulated design appears to perform well in terms of simplicity and spaceconscious structure in addition to exhibiting balance between transfer efficiency of $B 1$ and $B l$ without sacrificing peak transfer efficiency of either one.

Table 2. Simulated and measured peak transfer efficiency

\begin{tabular}{|c|c|c|c|c|c|c|c|c|}
\hline $\begin{array}{l}\text { Axial distance } \\
(\mathrm{mm})\end{array}$ & $\begin{array}{c}\operatorname{Sim} \_f_{p B I} \\
(\mathrm{MHz})\end{array}$ & $\begin{array}{c}\operatorname{SimPTE} E_{p B 1} \\
(\%)\end{array}$ & $\begin{array}{c}\operatorname{Sim}_{-} f_{p B 2} \\
(\mathrm{MHz})\end{array}$ & $\begin{array}{c}\operatorname{SimPTE}_{p B 2} \\
(\%)\end{array}$ & $\begin{array}{c}M e a \_f_{p B I} \\
(\mathrm{MHz})\end{array}$ & $\begin{array}{c}M e a P T E_{p B 1} \\
(\%)\end{array}$ & $\begin{array}{c}M e a f_{p B 2} \\
(\mathrm{MHz})\end{array}$ & $\begin{array}{c}\text { MeaPTE } E_{p B 2} \\
(\%)\end{array}$ \\
\hline 30 & 6.78 & 80.64 & 13.57 & 79.35 & 6.80 & 72.34 & 13.44 & 74.02 \\
\hline 32 & 6.78 & 76.69 & 13.50 & 76.99 & 6.72 & 67.74 & 13.36 & 70.23 \\
\hline 34 & 6.78 & 71.53 & 13.46 & 73.86 & 6.72 & 63.92 & 13.28 & 67.30 \\
\hline 36 & 6.78 & 65.67 & 13.44 & 70.16 & 6.72 & 57.65 & 13.28 & 64.02 \\
\hline 38 & 6.78 & 59.45 & 13.42 & 66.02 & 6.72 & 53.37 & 13.20 & 59.79 \\
\hline 40 & 6.78 & 53.24 & 13.41 & 61.64 & 6.72 & 47.81 & 13.20 & 58.26 \\
\hline 42 & 6.78 & 47.27 & 13.39 & 57.14 & 6.72 & 41.46 & 13.20 & 51.90 \\
\hline 44 & 6.78 & 41.67 & 13.39 & 52.69 & 6.72 & 35.17 & 13.20 & 45.37 \\
\hline 46 & 6.78 & 36.58 & 13.39 & 48.33 & 6.72 & 31.43 & 13.20 & 41.66 \\
\hline 48 & 6.78 & 31.96 & 13.38 & 44.16 & 6.72 & 27.77 & 13.20 & 38.29 \\
\hline 50 & 6.78 & 27.87 & 13.38 & 40.21 & 6.72 & 23.69 & 13.20 & 32.82 \\
\hline
\end{tabular}

Table 3. Comparison with other works

\begin{tabular}{|c|c|c|c|c|c|c|c|c|}
\hline Ref & B1 & $P T E_{B 1}(\%)$ & $B 2$ & $P T E_{B 2}(\%)$ & $\begin{array}{c}\mathrm{Z} \\
(\mathrm{mm})\end{array}$ & $\begin{array}{c}\text { TX Size } \\
\text { (Width } \times \text { Length) }\end{array}$ & RX Size & $\begin{array}{c}\text { Additional } \\
\text { Structure }\end{array}$ \\
\hline [19] & $\begin{array}{r}200 \\
\mathrm{kHz}\end{array}$ & 55 & $\begin{array}{l}6.78 \\
\mathrm{MHz}\end{array}$ & 74 & 50 & $120 \times 70 \mathrm{~mm}^{2}$ & $120 \times 70 \mathrm{~mm}^{2}$ & $\begin{array}{c}\text { Dual-band } \\
\text { Repeater }\end{array}$ \\
\hline$[10]$ & $\begin{array}{c}6.78 \\
\mathrm{MHz}\end{array}$ & 81 & $\begin{array}{l}13.56 \\
\mathrm{MHz}\end{array}$ & 66 & 50 & $200 \mathrm{~mm}$ (diameter) & $\begin{array}{c}200 \mathrm{~mm} \\
\text { (diameter) }\end{array}$ & No \\
\hline $\begin{array}{l}\text { This } \\
\text { work }\end{array}$ & $\begin{array}{l}6.78 \\
\mathrm{MHz}\end{array}$ & 72.34 & $\begin{array}{l}13.56 \\
\mathrm{MHz}\end{array}$ & 74.02 & 30 & $80 \times 90 \mathrm{~mm}^{2}$ & $80 \times 90 \mathrm{~mm}^{2}$ & No \\
\hline
\end{tabular}

Figure 6 reveals that consistency of simulated and measured peak transfer efficiency above $50 \%$ is feasible when operating distance is varied between $30 \mathrm{~mm}$ to $38 \mathrm{~mm}$. In order to compare the decline of transfer efficiency with distance $(\mathrm{m})$ usually at $1 / \mathrm{d}^{6}$ [23-24], the fitted equations derived from the simulated and measured plots are expressed by the following:

$$
\begin{gathered}
\operatorname{SimPTE}_{p B 1}=\frac{\alpha_{s}}{z^{1.88}} \\
\operatorname{SimPTE}_{p B 2}=\frac{\beta_{s}}{z^{1.24}} \\
\operatorname{MeaPTE}_{p B 1}=\frac{\alpha_{m}}{z^{1.95}}
\end{gathered}
$$




$$
\operatorname{MeaPTE} E_{p B 2}=\frac{\beta_{m}}{z^{1.38}}
$$

Where $\alpha_{s}=0.1, \beta_{s=1.1,} \alpha_{m}=0.1, \beta_{m=0} 0.6$

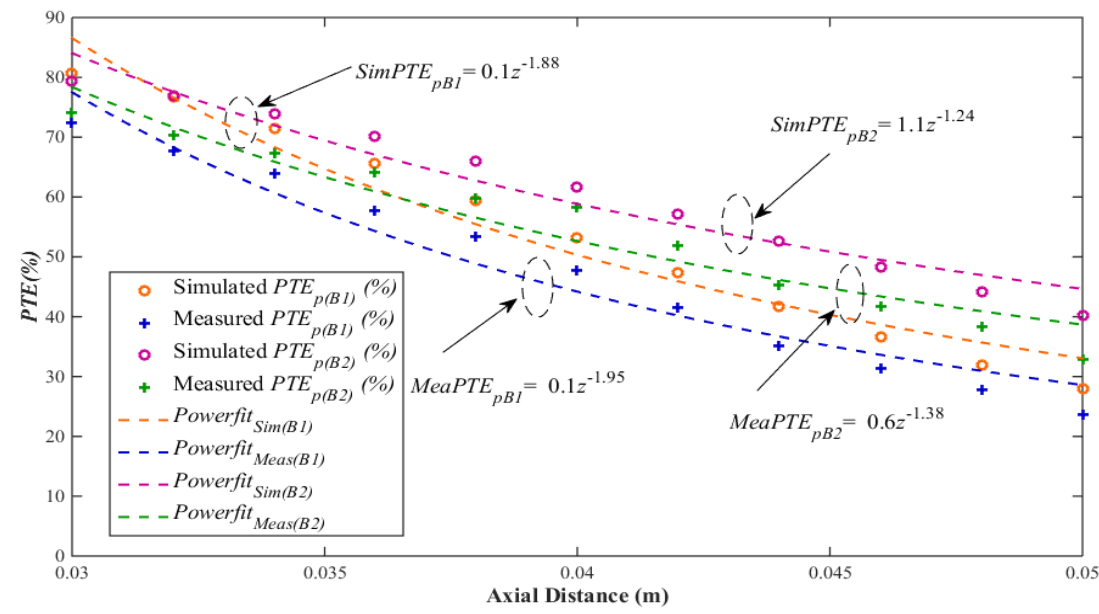

Figure 6. Simulated and measured peak transfer efficiencies for dual-band printed spiral resonator under axial displacement $(30 \mathrm{~mm} \leq \mathrm{z} \leq 50 \mathrm{~mm})$

\subsection{Fractional bandwidth}

The corresponding $-3 \mathrm{~dB}$ fractional bandwidths (FBW) are evaluated from combined $S_{11}$ and $S_{33}$ reflection coefficient plots as depicted in Figure 7. The axial distance between a pair of symmetrical WET printed spiral resonators selected is $30 \mathrm{~mm}$. Computed FBW at each band under observation is detailed in Table 4. This implies that the proposed design can be employed to facilitate adequate data transfer at B2. Fractional bandwidth [25] in percentage is expressed as:

$$
\mathrm{FBW}=\frac{100 \%(\Delta f)}{f_{c}}
$$

Table 4. Simulated and measured fractional bandwidth at $-3 \mathrm{~dB}$

\begin{tabular}{ccccccc}
\hline Band & $\operatorname{Sim}_{f} f_{c}(\mathrm{MHz})$ & $\operatorname{Sim} \_\Delta f(\mathrm{MHz})$ & Sim_FBW $(\%)$ & $M e a \_f_{c}(\mathrm{MHz})$ & $M e a \_\Delta f(\mathrm{MHz})$ & Mea_FBW $(\%)$ \\
\hline B1 & 6.8 & 1.1019 & 16.20 & 6.8 & 1.04 & 15.29 \\
B2 & 13.52 & 2.1173 & 15.66 & 13.44 & 2.24 & 16.67 \\
\hline
\end{tabular}

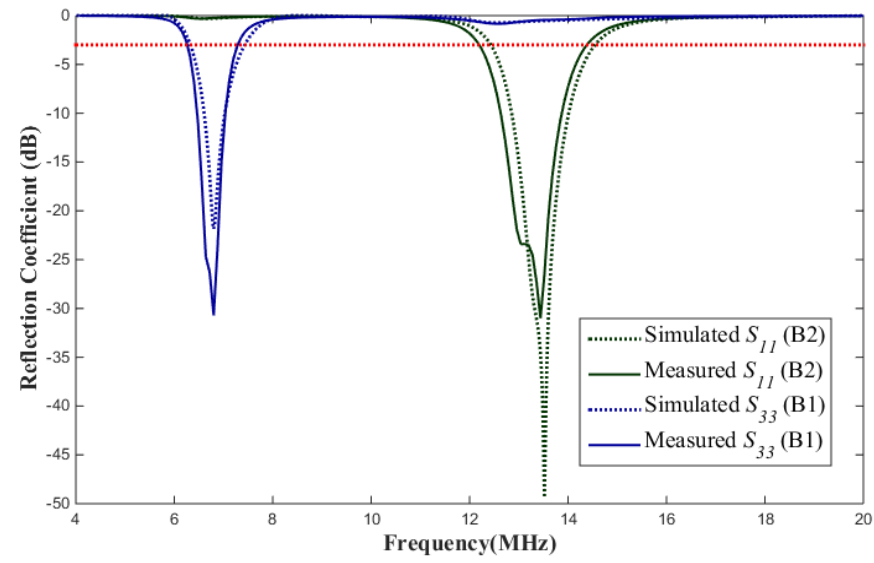

Figure 7. Reflection coefficient plots for dual-band printed spiral resonator 


\subsection{Port isolation}

The acceptable isolation for this design is established at $10 \mathrm{~dB}$ and above. As shown in Figure 8, the simulated isolation between trasmitters $\left(S_{31}\right)$ and receivers $\left(S_{42}\right)$ of both frequency bands are about $15 \mathrm{~dB}$ and $12 \mathrm{~dB}$ at $6.78 \mathrm{MHz}$ and $13.56 \mathrm{MHz}$ respectively. The corresponding measured $S_{31}$ and $S_{42}$ are about 11 $\mathrm{dB}$ and $10 \mathrm{~dB}$. Isolation between $B 1$ transmitter and $B 2$ receiver as well as between $B 2$ transmitter and $B 1$ receiver are represented by $S_{23}$ and $S_{41}$ plots. Approximate simulated isolation of $16 \mathrm{~dB}$ and $14 \mathrm{~dB}$ while measured isolation of $17 \mathrm{~dB}$ and $15 \mathrm{~dB}$ at $B 1$ and $B 2$ are observed. This indicate that the proposed design can be implemented for multifunctional wireless energy transfer applications by meeting minimal isolation design threshold.

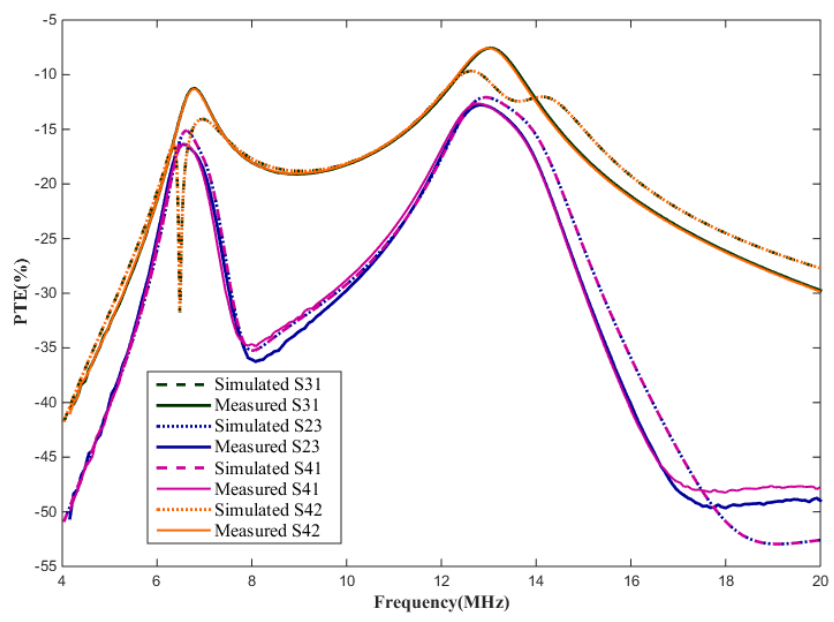

Figure 8. Transmission coefficient plots for dual-band printed spiral resonator

\section{CONCLUSION}

A single-layer dual-band printed spiral resonator is proposed and analyzed. This paper has essentially presented design approach based on electromagnetic full wave simulator. Design strategy employed is able to produce and achieve the targeted aim of transfer efficiency equilibrium between multiple bands without necessitating additional or intermediate loops, thereby maintaining a reduced footprint. Accomplishment in balance is inferred by the variation between transfer efficiency for both frequency bands under investigation which is only $1.68 \%$ at axial distance of $30 \mathrm{~mm}$. This also indicates its suitability for single transmitter device implementation in wireless energy transfer system. There is also a prospect shown in retaining transfer efficiency when symmetrical link is deliberately positioned under various axial distances.

\section{ACKNOWLEDGEMENTS}

This work was supported by Ministry of High-Education Malaysia (MOHE), Ericsson and Universiti Teknologi Malaysia (UTM) through Collaborative Research in Engineering, Science and Technology (CREST) and HiCOE Grant under vot numbers: 4J213, 4J216 and 4B151. This work was also supported in part by H2020-MSCA-RISE-2015 under Grant 690750, and in part by the Universiti Teknologi Malaysia under Grant 19H58 and Grant 04G37.

\section{REFERENCES}

[1] Wireless Power Consortium, "The Qi Wireless Power Transfer System Power Class 0 Specification Parts 1 and 2 : Interface Definitions," 2016.

[2] "A4WP Wireless Power Transfer System Baseline System Specification (BSS) v1.3," 2014.

[3] T. S. Chandrasekar Rao and K. Geetha, "Categories, Standards and Recent Trends in Wireless Power Transfer: A Survey," Indian J. Sci. Technol., vol. 9, no. 20, 2016.

[4] M. Chung, Y.-L. Chien, L. Cho, P. Hsu, and C.-F. Yang, "A dual-mode antenna for wireless charging and Near Field Communication," 2015 IEEE Int. Symp. Antennas Propag. Usn. Natl. Radio Sci. Meet., pp. 1288-1289, 2015. 
[5] D. Ahn and P. P. Mercier, "Wireless Power Transfer With Concurrent 200-kHz and 6.78-MHz Operation in a Single-Transmitter Device," IEEE Trans. Power Electron. Vol. 31, No. 7, July 2016, vol. 31, no. 7, pp. 5018-5029, 2016.

[6] W.-S. Lee, D.-Z. Kim, and J.-W. Yu, "Multi-functional high-isolation dual antenna for controllable wireless charging and NFC communication," Electron. Lett., vol. 50, no. 13, pp. 912-913, 2014.

[7] D. Kwon, T. D. Yeo, K. S. Oh, J. W. Yu, and W. S. Lee, "Dual Resonance Frequency Selective Loop of Near-Field Wireless Charging and Communications Systems for Portable Device," IEEE Microw. Wirel. Components Lett., vol. 25, no. 9, pp. 624-626, 2015.

[8] Guoxing Wang, Peijun Wang, Yina Tang, and Wentai Liu, "Analysis of Dual Band Power and Data Telemetry for Biomedical Implants," IEEE Trans. Biomed. Circuits Syst., vol. 6, no. 3, pp. 208-215, Jun. 2012.

[9] D. Ahn, S. Kim, S.-W. Kim, J. Moon, and I. Cho, "Wireless Power Transmitter and Receiver Supporting 200-kHz and 6.78-MHz Dual-Band Operation without Magnetic Field Canceling," Ieee Trans. Power Electron., vol. 32, no. 9, pp. 7068-7082, Sep. 2017.

[10] M. L. Kung and K. H. Lin, "Enhanced analysis and design method of dual-band coil module for near-field wireless power transfer systems," IEEE Trans. Microw. Theory Tech., vol. 63, no. 3, pp. 821-832, 2015.

[11] M. Dionigi and M. Mongiardo, "A novel resonator for simultaneous Wireless Power Transfer and Near Field Magnetic Communications," in IEEE MTT-S International Microwave Symposium Digest, 2012, no. 1, pp. 8-10.

[12] M. Han, J.-M. Kim, and H. Sohn, "Dual-mode wireless power transfer module for smartphone application," in 2015 IEEE International Symposium on Antennas and Propagation \& USNC/URSI National Radio Science Meeting, 2015, pp. 111-112.

[13] P. S. Riehl et al., "Wireless Power Systems for Mobile Devices Supporting Inductive and Resonant Operating Modes," IEEE Trans. Microw. Theory Tech., vol. 63, no. 3, pp. 780-790, Mar. 2015.

[14] K. Ding, Y. Yu, H. Lin, and D. R. C. Structure, "A Novel Dual-Band Scheme for Magnetic Resonant Wireless Power Transfer," Progress In Electromagnetics Research Letters, vol. 80, pp. 53-59, 2018.

[15] V. N. Yashchenko, D. S. Kozlov, and I. B. Vendik, "A dual-mode resonator for a dual-band wireless energy transfer system with possible simultaneous data transmission," Tech. Phys. Lett., vol. 41, no. 3, pp. 277-280, Mar. 2015.

[16] F. Tahar, A. Barakat, R. Saad, K. Yoshitomi, and R. K. Pokharel, "Dual-Band Defected Ground Structures Wireless Power Transfer System With Independent External and Inter-Resonator Coupling," IEEE Trans. Circuits Syst. II Express Briefs, vol. 64, no. 12, pp. 1372-1376, Dec. 2017.

[17] A. Barakat, K. Yoshitomi, and R. K. Pokharel, "Design and Implementation of Dual-Mode Inductors for Dual-Band Wireless Power Transfer Systems," IEEE Trans. Circuits Syst. II Express Briefs, vol. PP, no. c, p. 1, 2018.

[18] M. Kung and K. Lin, "A $6.78 \mathrm{MHz}$ and $13.56 \mathrm{MHz}$ dual-band coil module with a repeater for wireless power transfer systems," in 2016 IEEE International Symposium on Antennas and Propagation (APSURSI), 2016, pp. $157-158$

[19] M.-L. Kung and K.-H. Lin, "Dual-Band Coil Module With Repeaters for Diverse Wireless Power Transfer Applications," IEEE Trans. Microw. Theory Tech., vol. 66, no. 1, pp. 332-345, Jan. 2018.

[20] A. A. Eteng, S. K. Abdul Rahim, C. Y. Leow, B. W. Chew, and G. A. E. Vandenbosch, "Two-Stage Design Method for Enhanced Inductive Energy Transmission with Q-Constrained Planar Square Loops," PLoS One, vol. 11, no. 2, p. e0148808, Feb. 2016.

[21] A. Kurs, A. Karalis, M. Robert, J. D. Joannopoulos, P. Fisher, and M. Soljacic, "Wireless power transfer via strongly coupled magnetic resonances," Science, vol. 317, no. 5834, pp. 83-86, 2007.

[22] F. Jolani, Y. Yu, and Z. Chen, "A Planar Magnetically Coupled Resonant Wireless Power Transfer System Using Printed Spiral Coils," IEEE Antennas Wirel. Propag. Lett., vol. 13, pp. 1648-1651, 2014.

[23] O. Jonah, S. V Georgakopoulos, and M. M. Tentzeris, "Optimal Design Parameters for Wireless Power Transfer by Resonance Magnetic," IEEE Antennas Wirel. Propag. Lett., vol. 11, pp. 1390-1393, 2012.

[24] A. A. Eteng, S. K. A. Rahim, and C. Y. Leow," Wireless Nonradiative Energy Transfer: Antenna performance enhancement techniques," IEEE Antennas Propag. Mag., vol. 57, no. 3, pp. 16-22, Jun. 2015.

[25] C. a. Balanis," Frequency Independent Antennas, Antenna Miniaturization, and Fractal Antennas," in Antenna Theory: Analysis Design, Third Edition, 2005, p. wiley.

\section{BIOGRAPHIES OF AUTHORS}

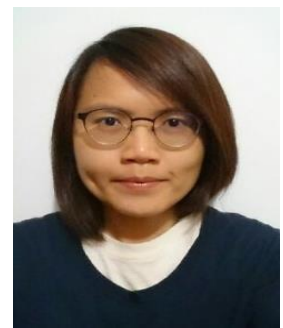

Lai Ly Pon received her Bachelor of Engineering (Electrical) and Master of Engineering (Electrical) from Universiti Teknologi Malaysia (UTM) in 2007 and 2010 respectively. She has spent five years working in various telecommunication industry. Currently, she is working towards her PhD. Degree in Wireless Communication Centre (WCC), UTM. Her research interests include near field wireless energy transfer; metamaterial, wireless propagation and mobile network system. 


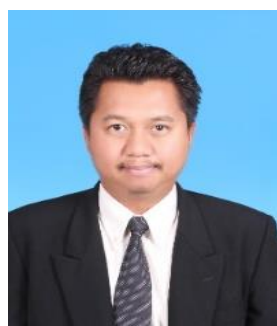

Sharul Kamal Abdul Rahim received the degree in electrical engineering from The University of Tennessee, USA, the M.Sc. degree in engineering (communication engineering) from Universiti Teknologi Malaysia (UTM), and the Ph.D. degree in wireless communication system from the University of Birmingham, U.K., in 2007. After his graduation from The University of Tennessee, he spent three years in industry. After graduating the M.Sc. degree, he joined UTM in 2001, where he is currently a Professor with the Wireless Communication Centre. He has published over 200 learned papers, including the IEEE Antenna and Propagation Magazine, the IEEE TRANSACTIONS ON ANTENNA AND PROPAGATION, IEEE ANTENNA AND PROPAGATION LETTERS, and taken various patents. His research interests include antenna design, smart antenna system, beamforming network, and microwave devices for fifth generation mobile communication. He is a Senior Member of IEEE Malaysia Section, a member of the Institute of Engineer Malaysia, a Professional Engineer with BEM, a member of the Eta Kappa $\mathrm{Nu}$ Chapter, University of Tennessee, and the International Electrical Engineering Honor Society. He is currently an Executive Committee of the IEM Southern Branch.

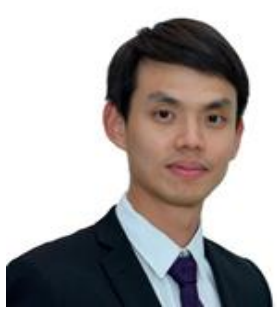

Chee Yen Leow obtained the B.Eng. degree in Computer Engineering from Universiti Teknologi Malaysia (UTM), Johor Bahru, Malaysia, and the Ph.D. degree from Imperial College London, U.K., in 2007 and 2011, respectively. Since July 2007, he has been an academic staff with the School of Electrical Engineering, Faculty of Engineering, UTM. He is currently an Associate Professor in the Faculty and a Research Fellow in the Wireless Communication Centre (WCC), Higher Institution Centre of Excellence, UTM and UTM-Ericsson Innovation Centre for 5G. His research interests include non-orthogonal multiple access, cooperative communication, UAV communication, MIMO, hybrid beamforming, physical layer security, wireless power transfer, convex optimization, game theory and prototype development using software defined radio, for $5 \mathrm{G}$ and IoT applications.

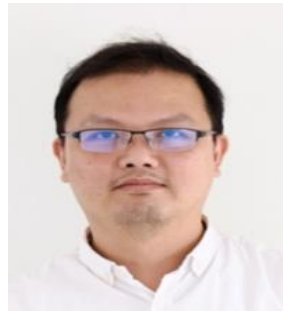

Tien Hua Chua received both the B.Sc. (Honours) degree in Electrical engineering (First Class) and the Master of Electrical Engineering in Wireless Engineering from the Universiti Teknologi Malaysia in 2003 and 2007, respectively. Tien Han was a Tutor (2005-2007) and then a Lecturer (2007-present) at the Faculty of Electrical Engineering, Universiti Teknologi Malaysia. He is currently on a 3-year study leave to pursue a Ph.D degree at the Computer Laboratory, University of Cambridge. His research interests include broadband fixed wireless access systems, radio propagation, channel modelling and measurement. 